\title{
The role of PET/CT in the evaluation of bone marrow involvement in lymphoma patients at the initial staging
}

\author{
Lenfoma hastalarında tanı anında evreleme amaçlı çekilen PET/CT'nin kemik iliği \\ infiltrasyonunu göstermedeki yeri
}

Fergun YILMAZ, Nur SOYER, Demet KIPER, Recep SAVAŞ, Nazan ÖZSAN, Fahri ŞAHIN, Güray SAYDAM, Mahmut TÖBÜ, Murat TOMBULOĞLU, Özgür ÖMÜR, Filiz VURAL

\begin{abstract}
Objective: Bone marrow (BM) involvement is one of the most important prognostic factors in lymphoma patients. Therefore, it is important to determine the presence of BM involvement in lymphoma patients at the time of diagnosis. Bone marrow biopsy (BMB) is still accepted as the gold standard for evaluating the marrow but it is painful and invasive. In this retrospective study, we aimed to evaluate the role of positron emission tomography combined with computed tomography (PET/CT) in evaluating the $\mathrm{BM}$ involvement in lymphoma patients at the initial staging.

Patients and Methods: The patients who were evaluated by PET/CT and bone marrow biopsy at time of diagnosis were enrolled in the study.

Results: The overall sensitivity of PET/CT in demonstrating BM involvement was $65.8 \%$, and the specificity was $89.4 \%$. In the subgroup analysis of 176 Hodgkin lymphoma (HL) patients, the sensitivity and specificity of the PET/CT were $81 \%$ and $84 \%$ respectively. Negative predictive value was $98 \%$. In 201 diffuse large B cell lymphoma (DLBCL) patients, the sensitivity and specificity of the test were $91.3 \%$ and $94.3 \%$, respectively. Negative predictive value was $98.8 \%$.

Conclusion: PET/CT is an accurate and complementary modality with high specificity and sensitivity in detecting BM infiltration in HL and DLBCL patients.
\end{abstract}

Keywords: PET/CT, Lymphoma, Bone marrow infiltration

Fergun Yilmaz (西), Demet Kiper

Hematology Clinic, İzmir Atatürk Training and Research Hospital, İzmir, Turkey

e-mail:fergunaydin@hotmail.com

Nur Soyer, Fahri Şahin, Güray Saydam, Mahmut Töbü, Murat Tombuloğlu, Filiz Vural

Department of Hematology, School of Medicine, Ege University, İzmir, Turkey Recep Savaş

Department of Radiology, School of Medicine, Ege University, İzmir, Turkey Nazan Özsan

Department of Pathology, School of Medicine, Ege University, İzmir, Turkey

Özgür Ömür

Department of Nuclear Medicine, School of Medicine, Ege University, İzmir, Turkey

Submitted / Gönderilme: 03.11.2016

Accepted/Kabul: 23.12.2016
Öz

Amaç: Kemik iliği (Kİ) tutulumu, lenfoma hastalarında en önemli prognostik faktörlerden biridir. Bu nedenle, tanı anında Kİ tutulumunun gösterilmesi önemlidir.Kemik iliği biyopsisi (KİB) tutulumu göstermede altın standart kabul edilmesine rağmen invaziv ve ağrılı bir yöntemdir. Bu retrospektif çalışmada, tanı anında evreleme amacıyla çekilen PET/CT'nin Kİ tutulumunu göstermedeki yerini araştırdık.

Hastalar ve Yöntemler : Tanı anında PET/CT ve KİB yapılan hastalar çalışmaya alındı.

Bulgular: PET/CT'nin lenfoma hastalarının Kİ tutulumunu göstermedeki sensitivitesi \%65.8, spesifisitesi ise \%89.4 idi. Altgrup analizi yapıldığında; 176 Hodgkin lenfoma hastasında sensitivite $\% 81$ ve spesifisite $\% 84$ olarak bulundu. Negatif prediktif değer \%98 idi. 201 diffüz büyük B hücreli lenfoma hastasında ise, sensitivite ve spesifisite sirasiyla $\% 91.3$ ve $\% 94.3$ idi. Negatif prediktif değer \%98.8 olarak hesaplandı.

Sonuç: PET/CT özellikle Hodgkin lenfoma ve difüz büyük B hücreli lenfoma hastalarında yüksek sensitivite ve spesifisitesi ile tamamlayıcı ve değerlendirilmesi gereken bir yöntemdir.

Anahtar kelimeler: PET/CT, Lenfoma, Kemik iliği tutulumu

\section{Introduction}

Lymphomas are the most common hematologic malignancies in the developed world. Bone marrow (BM) involvement occurs in 30-50\% in non-Hodgkin lymphoma (NHL) patients, especially in indolent subtypes [1]. BM involvement is one of the most important prognostic factors in lymphomas. It increases the stage of the disease to stage 4 according to Ann-Arbor staging system and is associated with poor prognosis [2]. Therefore, it is important to determine the presence of BM involvement in lymphoma patients at the time of diagnosis.

Bone marrow biopsy (BMB) is still accepted as the gold standard for evaluating the marrow. BMB is a painful 
and invasive procedure. Complications such as bleeding, infection, needle breakage, osteomyelitis and fractures, especially in osteoporotic patients can, though rarely, be seen $(0.05-0.07 \%)$. Even mortality directly related to the procedure has been reported [3]. Another disadvantage of $\mathrm{BMB}$ is that, it gives data pertaining to a limited area that is biopsied. Since the infiltration of lymphoma is usually focal, biopsy can miss the infiltration and the size of the biopsy may be too small to evaluate the infiltration. Although, some studies support the need for bilateral biopsies [4], others concluded that a specimen long enough (approximately 2 $\mathrm{cm}$ ) may obviate the need for bilateral sampling [5].

New strategies are being searched for evaluating the BM infiltration in lymphoma patients. One of these methods is positron emission tomography combined with computed tomography (PET/CT) using 18F-2-deoxy-2-(18F) fluoro-D-glucose (18F-FDG). It is a whole body imaging technique that gives functional information about the cells using the glucose metabolism. Metabolically active cells such as malignant cells use and take radio-labeled glucose more avidly and become visible. This method can be used for staging and assessing treatment response for various malignant tumors including aggressive NHL and Hodgkin lymphomas (HL) [6-8] but its role in demonstrating BM infiltration is not documented well at present. In this retrospective study, we compare the results of BMB and $\mathrm{PET} / \mathrm{CT}$ in terms of BM infiltration in lymphoma patients.

\section{Patients and Methods}

\section{Patients}

Four hundred and eighty-six adult patients older than 18 years of age diagnosed with lymphoma histopathologically according to World Health Organization (WHO) criteria [9] between March 2007 and August 2013 were retrospectively reviewed. $\mathrm{PET} / \mathrm{CT}$ and $\mathrm{BMB}$ data obtained at the time of diagnosis of patients were re-assessed. Data of the patients were collected from the archives of Departments of Hematology and Pathology. Age, sex, complete blood count, lactate dehydrogenase and beta-2 microglobulin were recorded. The maximum time between the PET/CT and BMB was 7 days. The patients were excluded if their BMBs were performed more than 7 days after PET/CT.

Using WHO criteria, anemia was defined as hemoglobin lower than $130 \mathrm{~g} / \mathrm{l}$ and $120 \mathrm{~g} / \mathrm{l}$ in males and females, respectively [10]. This study was approved by local ethics committee.

\section{Bone Marrow Biopsy}

BMBs were performed in the standard way from the iliac spine under local anesthesia. Patients with inadequate sample for interpretation were not enrolled in the study. Bone marrow sections were prepared and stained with haematoxylene-eosin after decalcification procedures of BMB specimens. All bone marrow biopsies were examined for infiltration of lymphoma by specialist hematopathologists. Using paraffin embedded whole tissue sections; immunohistochemical analysis was performed on an automated stainer (Ventana Benchmark XT; Ventana Medical Systems, Tucson, Arizona, USA) according to the standard protocols. Streptavidin-biotin-peroxidase detection system with diaminobenzidine (DAB) as chromogen was used to visualize bound secondary antibodies. In order to determine an infiltration, a panel of antibodies was used according to the initial diagnosis, which included CD3 (Novacastra clone LN10, Novacastra Laboratories Ltd, Newcastle, UK; dilution 1:200), CD20 (Dako clone L26, DakoCytomation Inc, Carpenteria, CA; dilution 1:250), Pax-5 (CONE:34, Thermo Scientific Lab Vision, USA, dilution 1:50), CD30 (Novacastra clone 1G12, Novacastra Laboratories Ltd, Newcastle, UK; dilution 1:100), Bcl-2 (Dako clone 124, DakoCytomation Inc, Carpenteria, CA; dilution 1:50). When necessary, other immunohistochemical analyses were also performed.

\section{PET/CT}

\section{FDG PET and Contrast-Enhanced Computed Tomography}

All patients underwent FDG-PET on a PET/CT unit (Discovery STE; GE, Milwaukee, USA). Patients fasted for at least 4 hours before imaging, and the glucose level in the peripheral blood was confirmed to be below $150 \mathrm{mg} /$ $\mathrm{dL}$ before FDG injection. $5.55 \mathrm{MBq} / \mathrm{kg}$ of body weight of FDG was administered intravenously (IV) an hour before the image acquisition. After the initial contrast-enhanced CT scan with 16-multidetector CT (GE), a standard PET protocol was used in the $3 \mathrm{D}$ mode to scan the area from the vertex of the skull to the pelvic region with an acquisition time of 3 minutes per bed position.

Scanning was performed using the helical technique after injection of contrast medium to the patients whilst in the supine position. A total dose of $100-130 \mathrm{~mL}$ iodinated contrast media (iopromide, Bayer Pharma AG, Berlin ,Germany) was administered IV at a rate of $3 \mathrm{~mL} / \mathrm{s}$ by an 
automatic injector. Written informed consents were obtained before PET/CT examination from each patient.

\section{Image Analysis}

Fluoro-D-Glucose/positron emmision tomography images were viewed at interactive workstations (Advantage Workstation AW4.6, GE Healthcare) by the same consultant in nuclear medicine and same radiologist both of whom are experienced in oncological imaging. Bone marrow FDG uptake was assessed visually in comparison to the liver uptake. The standardized uptake value (SUV) measurements were also obtained for each of the 3 larger homogeneous vertebrae visible in the field of view (L3, L4, and L5 or S1). A region of interest (ROI) was drawn over the vertebral body, using an automatic isocontour ROI set at $75 \%$ of the maximum SUV. The bone marrow SUV was defined as the mean value of the 3 selected vertebrae; vertebrae SUV values higher than the liver were considered as a sign of bone marrow involvement [11]. The absence of tracer uptake or lowgrade uptake (less than or equal to liver parenchyma intensity) in the marrow sites was interpreted as absence of disease activity. Tracer uptake of moderate to intense degree (more than liver parenchyma intensity) was interpreted as presence of disease involvement. This was performed as a ratio of SUVmax values obtained from a suitable circular ROI over the spine in patients with bone marrow tracer uptake interpreted as presence of disease metabolic activity on qualitative assessment.

\section{Statistical analysis}

Continuous data were expressed as median (minimummaximum), and qualitative data were expressed as number of cases and percentages. Patients were categorized according to the status of BM infiltration according to the BMB and 18F-FDG PET/CT results. Correlations between FDG PET/ $\mathrm{CT}$ and available pathological findings were examined. All positive pathological findings of BMB were considered as true-positive results. A finding of abnormal focal or multifocal increase in FDG uptake by the BM in the initial $\mathrm{PET} / \mathrm{CT}$ study was considered true positive if the patient had corresponding pathologically confirmed lymphoma with BMB. Sensitivity, specificity, positive predictive value (PPV), and negative predictive value (NPV) of FDG PET/ $\mathrm{CT}$ against $\mathrm{BMB}$ were presented for the assessment of $\mathrm{BM}$ involvement by lymphoma.

\section{Results}

Four hundred and eighty-six newly diagnosed lymphoma patients (208 females, 278 males) who underwent both PET/ $\mathrm{CT}$ and BMB were evaluated retrospectively. The median age was 45 years (range: $18-87$ years). BM infiltration was documented in 79 patients with BMB, 95 patients with $\mathrm{PET} / \mathrm{CT}$ and 52 patients with both procedures. There was discordance between the procedures in 70 patients (43 patients with negative BM infiltration and positive PET/ CT; 27 patients with negative PET/CT for BM involvement but positive $\mathrm{BMB}$ ). The characteristics of the patients were summarized in Table I.

Table I: Characteristics of the patients

\begin{tabular}{|l|c|c|c|}
\hline & All patients & $\begin{array}{c}\text { Non-Hodgkin } \\
\text { lymphoma }\end{array}$ & $\begin{array}{c}\text { Hodgkin } \\
\text { lymphoma }\end{array}$ \\
\hline Number of patients & 486 & 310 & 176 \\
\hline Age, years (range) & $45(18-87)$ & $59(18-87)$ & $38(18-79)$ \\
\hline Sex (male/female) & $(278 / 208)$ & $(173 / 137)$ & $(105 / 71)$ \\
\hline Involvement in PET/CT (yes/no) & $95 / 391$ & $60 / 250$ & $35 / 141$ \\
\hline Involvement in BMB (yes/no) & $78 / 408$ & $67 / 243$ & $11 / 165$ \\
\hline Anemia (yes/no) & $178 / 181^{*}$ & $106 / 119^{*}$ & $72 / 62^{*}$ \\
\hline Beta 2 level (normal/high) & $108 / 53^{*}$ & $71 / 38^{*}$ & $37 / 15^{*}$ \\
\hline LDH level (normal /high ) & $236 / 139^{*}$ & $145 / 95^{*}$ & $91 / 44^{*}$ \\
\hline
\end{tabular}

* Data of other patients are not available, PET/CT: positron emission tomography combined with computed tomography, BMB: bone marrow biopsy, LDH: lactate dehydrogenase

Since the BMB is still regarded as gold standard for evaluating BM infiltration, we compared the PET/ $\mathrm{CT}$ imaging findings with $\mathrm{BMB}$ results in terms of $\mathrm{BM}$ infiltration. The overall sensitivity of PET/CT in demonstrating BM involvement in all lymphoma patients was $65.8 \%$, and the specificity was $89.4 \%$. As the lymphoma patients were very heterogeneous, we performed subgroup analysis, separating HL and NHL patients.

\section{HL Patients}

There were 176 ( 71 females, 105 males) HL patients with the median age of 38 years (range: 18-79 years). BM 
infiltration was documented in $11 \mathrm{HL}$ patients with BMB while PET/CT depicted a high SUV value consistent with $\mathrm{BM}$ infiltration in 35 patients. The tests were comparable in 148 patients (both documented infiltration in 9 patients and neither documented infiltration in 139 patients). There was discordance between the tests in 28 of HL patients (Table II).

Table II: The results of PET/CT and BMB in HL patients

\begin{tabular}{|cc|c|c|}
\cline { 3 - 4 } \multicolumn{1}{c|}{} & \multicolumn{2}{c|}{ PET/CT infiltration } \\
\cline { 3 - 4 } \multicolumn{1}{c|}{} & YES & NO \\
\hline $\begin{array}{c}\text { BMB } \\
\text { infiltration }\end{array}$ & YES & 9 & 2 \\
\cline { 3 - 4 } & NO & 26 & 138 \\
\hline
\end{tabular}

BMB: bone marrow biopsy, PET/CT: positron emission tomography combined with computed tomography, HL: Hodgkin lymphoma patients

Although the BMB was negative for infiltration, PET/ CT depicted high uptake (more than liver); in 26 patients with HL which can be interpreted in favor of involvement. In three of these patients, the BM was hypercellular without infiltration. Twenty patients were either anemic or had leukocytosis $\left(>10000 / \mathrm{mm}^{3}\right)$. The laboratory tests were consistent with iron deficiency anemia in 6 of the anemic patients and anemia of chronic disease in the remaining anemic patients. The discordance could not be accounted for in 3 patients.

Among the HL patients, the sensitivity and specificity of the test were $81 \%$ and $84 \%$, respectively. False positivity and false negativity was calculated as $18 \%$ and $16 \%$, respectively. PPV and NPV was $25.7 \%$ and $98 \%$, respectively (Table III).

\section{NHL Patients}

The subgroup of NHL patients comprised of 310 patients with diffuse large B cell lymphoma (DBBCL- 201 patients), follicular lymphoma (22 patients), mantle cell lymphoma (18 patients), marginal zone lymphoma (12 patients), low grade B cell lymphoma- nonspecified ( 3 patients), T- cell lymphoma (11 patients), anaplastic large B cell lymphoma (13 patients), Burkitt lymphoma (9 patients), small lymphocytic lymphoma (21 patients) were analyzed retrospectively. The most common subtype was DBBCL. Since high and low grade lymphomas were heterogeneous groups, the subgroup analysis in NHL patients was performed for the DLBCL group.

There were 201 DLBCL patients ( 88 females and 113 males). The median age was 59 years (range: 21-87 years). In 178 DLBCL patients, BMB showed no infiltration while in 23 patients it revealed lymphoma infiltration. PET/CT and BMB were consistent in 189 patients (21 patients were reported having $\mathrm{BM}$ involvement with both tests and there was no BM infiltration with either test in 168 patients). There was discordance between the tests in 12 patients (Table IV). There were two patients in whom PET/CT missed the infiltration of BM documented by biopsy. In 10 patients, PET/CT indicated infiltration while it could not be confirmed by BMB. Five of them had anemia consistent with chronic disease, three of them had leukocytosis and 2 of them had thrombocytosis which could explain the high activity of the bone marrow and positive PET/CT results.

In subgroup analysis of the DLBCL patients showed that the sensitivity and specificity of the test were $91.3 \%$ and $94.3 \%$, respectively. False positivity and false negativity was calculated as $5.6 \%$ and $8.6 \%$, respectively. PPV and NPV were $67.7 \%$ and $98.8 \%$, respectively (Table III). There was not a spesific subgroup in DLBCL patients with a higher spesificity or sensitivity.

Table III: Statistical measures of the performance of PET/CT (\%) in HL patients and DLBCL

\begin{tabular}{|c|c|c|c|c|c|c|c|}
\hline & Sensitivity & Specificity & False negative ratio & False positive ratio & Accuracy & $\begin{array}{c}\text { Positive } \\
\text { predictive value }\end{array}$ & $\begin{array}{c}\text { Negative } \\
\text { predictive value }\end{array}$ \\
\hline HL & 81 & 84 & 16 & 18 & 84 & 25.7 & 98 \\
\hline DLBCL & 91.3 & 94.3 & 8.6 & 5.6 & 94 & 67.7 & 98.8 \\
\hline
\end{tabular}

HL: Hodgkin lymphoma, DLBCL: diffuse large B cell lymphoma, PET/CT: positron emission tomography combined with computed tomography 
Table IV: The results of PET/CT and BMB in DLBCL patients

\begin{tabular}{|cc|c|c|}
\cline { 3 - 4 } \multicolumn{1}{c|}{} & \multicolumn{2}{c|}{ PET/CT infiltration } \\
\multicolumn{1}{c|}{} & YES & NO \\
\hline BMB & YES & 21 & 2 \\
\cline { 3 - 4 } infiltration & NO & 10 & 168 \\
\hline
\end{tabular}

BMB: bone marrow biopsy, PET/CT: positron emission tomography combined with computed tomography, DLBCL: diffuse large B cell lymphoma

\section{Discussion}

Positron emission tomography combined with computed tomography is being used increasingly for the initial staging and response evaluation in lymphoma patients. Although, its overall usefulness is not well documented in low-grade lymphomas, its role is well established in staging and response evaluation in HL and aggressive NHL patients $[12,13]$. Its value in showing the BM infiltration in lymphoma patients remains unclear and BMB is still the gold standard for evaluating the infiltration although it has some limitations. In this retrospective study, we compared the demonstration of BM infiltration with BMB and PET/ CT which were performed at the time of diagnosis. Because FDG uptake can be affected by various chemotherapies and granulocyte stimulating factors, PET/CT reports obtained before the onset of the therapy were taken into account. The overall sensitivity and specificity of PET/CT against BMB was calculated as $65.8 \%$ and $89.4 \%$, respectively. A metaanalysis performed by Pakos et al. found the sensitivity and specificity as $51 \%$ and $91 \%$, respectively [14]. In this metaanalysis, no major subgroup differences have been reported in retrospective and prospective studies and the better sensitivity was shown in HL and aggressive NHL patients, a finding which is in agreement with our results [14].

Subgroup analysis of HL patients showed that the sensitivity and specificity of the PET/CT were $81 \%$ and $84 \%$, respectively. In various research studies and metaanalyses conducted on HL patients, the sensitivity is in the range of $78.6-100 \%$, which is consistent with our results. The specificity is also high, ranging between $76.5-100 \%$ [15-18].

In 26 patients, although the BMB was negative for infiltration, PET/CT showed high FDG uptake which may be an indicator of BM involvement. In these patients, leukocytosis, anemia and hypercellular bone marrow were noted. High uptake may be related to active bone marrow rather than infiltration. But due to the fact that it was a retrospective study, we were unable to perform a rebiopsy from the sites of high FDG uptake to re-assess the infiltration. In a meta-analysis, 6 of 12 patients with negative $\mathrm{BMB}$ and positive $\mathrm{PET} / \mathrm{CT}$ were found to be positive in $\mathrm{BMB}$ when the biopsies were repeated according to PET/CT uptake signals [14].

Positive predictive value and NPV of PET/ CT in HL patients were $25.7 \%$ and $98 \%$ in our study. Muzahir et al., reported PPV and NPV to be $29.72 \%$ and $76.57 \%$ [16]. In a recent meta-analysis, pooled PPV and NPV as high as $97.6 \%$ and $98.8 \%$, respectively have been reported [15]. Although, the NPV calculated in our study is consistent with this analysis, PPV is lower in the present study. In the present study, we took BMB as gold standard for evaluating BM infiltration. Therefore, we considered some FDGavid lesions in PET/CT which could be indicative of true infiltration as false positive based on the negative results in blind BMB. Furthermore, it should be noted that the BMB may not show all the lymphomatous infiltration. BMB may reveal positive infiltration if the biopsy is repeated according to FDG-avid sites. This may explain the low PPV in our study $[15,16,19,20]$.

Non-Hodgkin lymphoma is a heterogeneous group of patients with low and high grade lymphomas with different properties. In the literature, there was a significant difference in the capability of PET/CT to detect BM infiltration according to histological type of NHL. It has been reported in the literature that the performance of PET/ $\mathrm{CT}$ in evaluating the BM infiltration in indolent lymphomas was poor $[18,21]$. Since, indolent lymphomas comprise a number of different lymphoma types, we did not perform a subgroup analysis in this heterogeneous group.

Chen and et al., reported that the performance of PET/CT was better in the aggressive lymphoma group [21]. Among the aggressive lymphoma patients, DLBCL patients constituted the majority of the patients (201 patients, $64 \%$ of all NHL). Therefore, in this retrospective analysis, DLBCL were chosen for subgroup analysis among aggressive lymphoma patients. The sensitivity and specificity of the test against BMB were $91.3 \%$ and $94.3 \%$ respectively. There was discordance in $12(6 \%)$ patients. PPV and NPV were $67.7 \%$ and $98.8 \%$, respectively. Cortés-Romera et al., analyzed 147 lymphoma patients (84 DLBCL, 63 HL) [22]. The concordant and discordant results were observed between $\mathrm{PET} / \mathrm{CT}$ and $\mathrm{BMB}$ in $19(14 \%)$ and 128 patients (87\%), respectively. The 
sensitivity, specificity, accuracy, as well as PPV and NPV of FDG-PET/CT for the detection of BM infiltration were $95 \%, 86 \%, 87 \%, 54 \%$, and $99 \%$, respectively. In a meta-analysis with newly diagnosed DLBCL patients, the sensitivity of FDG PET/CT for detecting BM involvement ranged between $70.8 \%$ to $95.8 \%$ while the specificity was in the range of $99.0 \%$ to $100 \%$, with pooled estimates of $88.7 \%$ (95\% confidence interval, CI, $82.5-93.3 \%)$ and 99.8\% (95\% CI, 98.8 - 100\%), respectively [23]. These results are comparable to ours.

In 10 DLBCL patients, PET/CT revealed infiltration while could not be confirmed by BMB. Five of these patients had anemia consistent with chronic disease, three patients had leukocytosis and two patients had thrombocytosis, which all can be held accountable for high activity of the bone marrow and positive PET/CT results. Positive results in PET/CT should be interpreted carefully if they are not confirmed by biopsy because false positive results may be due to chemotherapy, granulocyte colony stimulating factors, infection/inflammation, or hyperplastic bone marrow [24, 25].

False negative results with $\mathrm{BMB}$ due to focal infiltration should also be taken into account and repeat biopsy should be considered for the FDG-avid sites. PET/CT guided biopsy will increase the accuracy of BMB [19].

In our study, PET/CT missed the infiltration in 2 patients with DLBCL and 2 patients with HL. False negative results may be due to diffuse low density marrow involvement or low FDG uptake per cell [12, 21].

In the light of these data, PET / CT is an accurate and complementary test with high specificity and sensitivity in detecting BM infiltration, which also gives a prognostic information in DLBCL and HL patients [23, 26, 27]. On the other hand, there are also studies in which the authors argued that PET/CT had limited value in detecting BM involvement [28].

There are limitations of the present study. First, it was a retrospective study on a heterogeneous group of patients at different stages of diseases. Second, the unilateral iliac crest biopsies were carried out blindly and we could not perform a repeat biopsy in patients with negative BMB and positive PET/CT results, which may be the source of the lower PPV of the PET/CT. Lastly, since this retrospective study did not involve the follow up period of the patients, the effect of bone marrow involvement detected by PET/CT on survival and response rates could not be determined.
In conclusion, although BMB is still the gold standard to assess BM infiltration in lymphoma patients, it is a painful and stressful procedure for the patients. It is mostly considered safe but adverse effects such as hemorrhage, infection are also reported. Hence, since PET/CT is a noninvasive, painless and more comfortable procedure than biopsy, it could be an alternative to BMB for initial staging in especially HL and DBBCL patients in the future. However, prospective studies with larger sample size, more homogenous groups and involving follow-up periods are needed to detect the performance of PET/CT in establishing the infiltration and its effects on survival.

\section{References}

1. Conlan MG, Bast M, Armitage JO, Weisenburger DD. Bone marrow involvement by non-Hodgkin's lymphoma: the clinical significance of morphologic discordance between the lymph node and bone marrow. Nebraska Lymphoma Study Group. J ClinOncol 1990;8:1163-72.

2. Rosenberg SA. Validity of the Ann Arbor staging classification for the non-Hodgkin's lymphomas. Cancer Treat Rep 1977;61:1023-7.

3. Bain BJ. Morbidity associated with bone marrow aspiration and trephine biopsy - a review of UK data for 2004. Haematologica 2006;91:1293-4.

4. Juneja SK, Wolf MM, Cooper IA. Value of bilateral bone marrow biopsy specimens in non-Hodgkin's lymphoma. J Clin Pathol 1990;43:630-2.

5. Campbell JK, Matthews JP, Seymour JF, Wolf MM, Juneja SK; Australasian Leukaemia Lymphoma Group. Optimum trephine length in the assessment of bone marrow involvement in patients with diffuse large cell lymphoma. Lymphoma Group Ann Oncol 2003;14:273-6.

6. Wirth A, Seymour JF, Hicks RJ, et al. Fluorine-18 fluorodeoxyglucose positron emission tomography, gallium-67 scintigraphy, and conventional staging for Hodgkin's disease and non-Hodgkin's lymphoma. Am J Med 2002;112:262-8.

7. Hernandez-Maraver D, Hernandez-Navarro F, GomezLeon $\mathrm{N}$, et al. Positron emission tomography/computed tomography: diagnostic accuracy in lymphoma. $\mathrm{Br} \mathrm{J}$ Haematol 2006;135:293-302.

8. Freudenberg LS, Antoch G, Schütt P, et al. FDG-PET/CT in re-staging of patients with lymphoma. Eur J Nucl Med Mol Imaging 2004;31:325-9.

9. Swerdlow SH, Campo E, Harris NL, et al. World Health Organization Classification of Tumours of Haematopoietic and Lymphoid Tissues. Lyon:IARC Press, 2008.

10. World Health Organization. Nutritional anaemias: Report of a WHO scientific group. Geneva, Switzerland 1968.

11. Hong J, Lee Y, Park Y, et al. Role of FDG PET/CT in detecting lymphomatous bone marrow involvement in patients with 
newly diagnosed diffuse large B-cell lymphoma. Ann Hematol 2012; 91:687-95. doi: 10.1007/s00277-011-1353-6

12. Elstrom R, Guan L, Baker G, et al. Utility of FDG-PET scanning in lymphoma by WHO classification. Blood 2003;101:3875-6.

13. Tsukamoto N, Kojima M, Hasegawa M, et al. The usefulness of (18)F-fluorodeoxyglucose positron emission tomography ((18)F-FDG-PET) and a comparison of (18)F-FDG-pet with (67)gallium scintigraphy in the evaluation of lymphoma: relation to histologic subtypes based on the World Health Organization classification. Cancer 2007;110:652-9.

14. Pakos EE, Fotopoulos AD, Ioannidis JP. 18F-FDG PET for evaluation of bone marrow infiltration in staging of lymphoma: a meta-analysis. J Nucl Med 2005;46:958-63.

15. Cheng G, Alavi A.Value of 18 F-FDG PET versus iliac biopsy in the initial evaluation of bone marrow infiltration in the case of Hodgkin's disease: a meta-analysis. Nucl Med Commun 2013;34:25-31. doi: 10.1097/MNM.0b013e32835afc19

16. Muzahir S, Mian M, Munir I, et al. Clinical utility of ${ }^{18} \mathrm{~F}$ FDG-PET/CT in the detection of bone marrow disease in Hodgkin's lymphoma.Br J Radiol 2012;85:490-6. doi: 10.1259/bjr/29583493

17. Agrawal K, Mittal BR, Bansal D, et al. Role of F-18 FDG $\mathrm{PET} / \mathrm{CT}$ in assessing bone marrow involvement in pediatric Hodgkin's lymphoma. Ann Nucl Med 2013;27:146-51. doi: 10.1007/s12149-012-0665-5

18. Mittal BR, Manohar K, Malhotra P. Can fluorodeoxyglucose positron emission tomography/computed tomography avoid negative iliac crest biopsies in evaluation of marrow involvement by lymphoma at time of initial staging? Leuk Lymphoma 2011;52:2111-6. doi: 10.3109/10428194.2011.593273

19. Cheng G, Chen W, Chamroonrat W, et al. Biopsy versus FDG $\mathrm{PET} / \mathrm{CT}$ in the initial evaluation of bone marrow involvement in pediatric lymphoma patients.Eur J Nucl Med Mol Imaging 2011;38:1469-76. doi: 10.1007/s00259-011-1815-Z

20. Schaefer NG, Strobel K, Taverna C, Hany TF. Bone involvement in patients with lymphoma: the role of
FDG-PET/CT. Eur J Nucl Med Mol Imaging 2007;34:60-7.

21. Chen YK, Yeh CL, Tsui CC, Liang JA, Chen JH, Kao CH.. F-18 FDG PET for evaluation of bone marrow involvement in non-Hodgkin lymphoma: a meta-analysis.Clin Nucl Med 2011;36:553-9. doi: 10.1097/RLU.0b013e318217aeff.

22. Cortés-Romera M, Sabaté-Llobera A, MercadalVilchez S. Bone Marrow Evaluation in Initial Staging of Lymphoma: 18F-FDG PET/CT Versus Bone Marrow Biopsy. Clin Nucl Med 2014;39:46-52. doi: 10.1097/ RLU.0b013e31828e9504.

23. Adams HJ, Kwee TC, de Keizer B, Fijnheer R, de Klerk JM, Nievelstein RA. FDG PET/CT for the detection of bone marrow involvement in diffuse large B-cell lymphoma: systematic review and meta-analysis.Eur J Nucl Med Mol Imaging 2014;41:565-74. doi: 10.1007/s00259-013-2623-4

24. Muslimani AA, Farag HL, Francis S. The utility of 18-F-fluorodeoxyglucose positron emission tomography in evaluation of bone marrow involvement by non-Hodgkin lymphoma Am J ClinOncol 2008;31:409-12. doi: 10.1097/ COC.0b013e318168d90b

25. Moog F, Bangerter M, Kotzerke J, Guhlmann A, Frickhofen N, Reske SN. 18-F-fluorodeoxyglucose-positron emission tomography as a new approach to detect lymphomatous bone marrow. J ClinOncol 1998;16:603-9.

26. Berthet $\mathrm{L}$, Cochet $\mathrm{A}$, Kanoun $\mathrm{S}$, et al. In newly diagnosed diffuse large B-cell lymphoma, determination of bone marrow involvement with $18 \mathrm{~F}-\mathrm{FDG} \mathrm{PET} / \mathrm{CT}$ provides better diagnostic performance and prognostic stratification than does biopsy. J Nucl Med 2013;54:1244-50. doi: 10.2967/ jnumed.112.114710.

27. Khan AB, Barrington SF, Mikhaeel NG, et al. PET-CT staging of DLBCL accurately identifies and provides new insight into the clinical significance of bone marrow involvement. Blood 2013;122:61-7. doi: 10.1182/blood-2012-12-473389

28. Hong J, Lee Y, Park Y. Role of FDG-PET/CT in detecting lymphomatous bone marrow involvement in patients with newly diagnosed diffuse large B-cell lymphoma. Ann Hematol 2012;91:687-95. doi: 10.1007/s00277-011-1353-6. 